\title{
Ambipolar Charge Carrier Transport in Organic Semiconductor Blends
}

Markus Bronner, Andreas Opitz, and Wolfgang Brütting

\section{1}

\section{Introduction}

Organic semiconductors have attracted considerable interest due to their growing potential as active materials in electronic and optoelectronic devices. A long-standing paradigm, however, has been their unipolar transport of electrical charges. This means that, apart from very few exceptions, until recently organic semiconductors have shown electrical conduction for one carrier species only, with positive carriers being preferentially transported in most materials. Nevertheless, both electron and hole transport were observed many years before in organic single crystals with photo generated charge carriers [1]. Thereby almost equal electron and hole mobilities with a temperature dependence indicative for band transport were obtained. This indicates that there is $a$ priori no intrinsic asymmetry between the transport of electrons and holes in the bulk of high-purity organic semiconductors.

In organic field-effect transistors (OFETs) the transport of carriers is limited in addition to the intrinsic material properties by the injection from the electrodes and by traps at the organic/insulator interface. Thus for many years, OFETs were reported to show either p- or n-type behaviour (see, e.g., Ref. [2] for an overview of materials). Ambipolar transport in OFETs was observed for the first time by Meijer et al. using mixtures of a soluble poly(phenylenevinylene) derivative (MDMO-PPV) and a fullerene derivative (PCBM) [3], which are known from bulk-heterojunction solar cells [4]. The phenomenon of ambipolar transport itself was reported already in the 1970s in the context of hydrogenated amorphous silicon thin film transistors [5]. Meanwhile ambipolar OFETs, where two different materials for electron and hole transport are used, have been realised with a variety of material combinations, including polymer/fullerene blends [3], mixtures of soluble oligomers [6] as well as evaporated molecular hetero-layer structures and mixed layers [7-11]. However, even in neat films of a single organic semiconductor ambipolar transport can be observed provided that the barrier for electron injection is reduced by choosing low-work function metals as source/drain electrodes. It has been 
demonstrated, e.g., that electron transport can be obtained in pentacene when $\mathrm{Ca}$ is used as electrode material $[12,13]$. Another possibility to get electron transport in traditionally p-conducting materials is to suppress electron trapping at the interface to the gate-dielectric by surface functionalisation or suitable polymeric dielectrics. A detailed report on polymeric dielectrics is given in Chapter 24 by Benson et al. For example, if silicon oxide is used as the insulator, the surface usually contains hydroxyl groups acting as electron traps. It has been shown that terminating these $\mathrm{OH}$-groups by silanisation [14] or interface doping by calcium [15] are suitable tools to achieve ambipolar transport in a large variety of materials. Recently, also low-band gap materials have been suggested as further candidates for ambipolar OFETs [16, 17]. Due to their small energy gap (sometimes below $1 \mathrm{eV}$ ) and suitable molecular energy levels (ionisation energy and electron affinity) the injection of both carrier species is easily obtained with a single metal for source and drain electrodes.

In this work we have chosen the combination of hole-conducting copperphthalocyanine $(\mathrm{CuPc})$ and the $\mathrm{n}$-conducting fullerene $\mathrm{C}_{60}$, which are both known from organic photovoltaic cells either as heterolayer structures or bulkheterojunctions [18-21]. They can be considered as model systems for ambipolar transport where the asymmetry of the electron and hole mobilities is adjustable by the concentration of both materials in the mixture.

Figure 17.1 shows a sketch of the ambipolar operation of an FET and the respective charge carrier distribution. The unipolar regime with $\left|V_{\mathrm{D}}\right|<\left|V_{\mathrm{G}}-V_{\mathrm{T}}\right|$ is dominated by the transport of only one charge carrier species - either electrons or holes, depending on the material and the electrodes. In the ambipolar regime both electrons and holes are injected into the semiconductor. This occurs in the regime where in the transfer characteristics (constant drain voltage) the unipolar FET is normally in the OFF state. Furthermore, for the opposite sign of $V_{\mathrm{D}}$ and $V_{\mathrm{G}}-V_{\mathrm{T}}$ even reversed unipolar transport can be observed in this case. The charge carrier distribution shows the decrease of charge carrier concentration inside the channel [22] and indicates the location where electrons and holes recombine. The position of this recombination zone depends on the applied voltages and can be shifted inside the channel as observed in ambipolar light-emitting FETs [23-25].

\section{2}

\section{Materials, Device Preparation and Experimental Methods}

Copper-phthalocyanine ( $\mathrm{CuPc}$, purchased from Aldrich as sublimation grade) and buckminster fullerene $\left(\mathrm{C}_{60}\right.$, purchased from Hoechst as super gold grade) were used as hole and electron conducting materials, respectively. The structural formulae are given in Figure 17.2a. The materials were deposited by thermal evaporation from low-temperature effusion cells in a vacuum of better than $1 \times 10^{-7}$ mbar to form neat and mixed layers with a thickness of about $25 \mathrm{~nm}$ on prestructured substrates to realise a bottom-gate and bottom-contact 


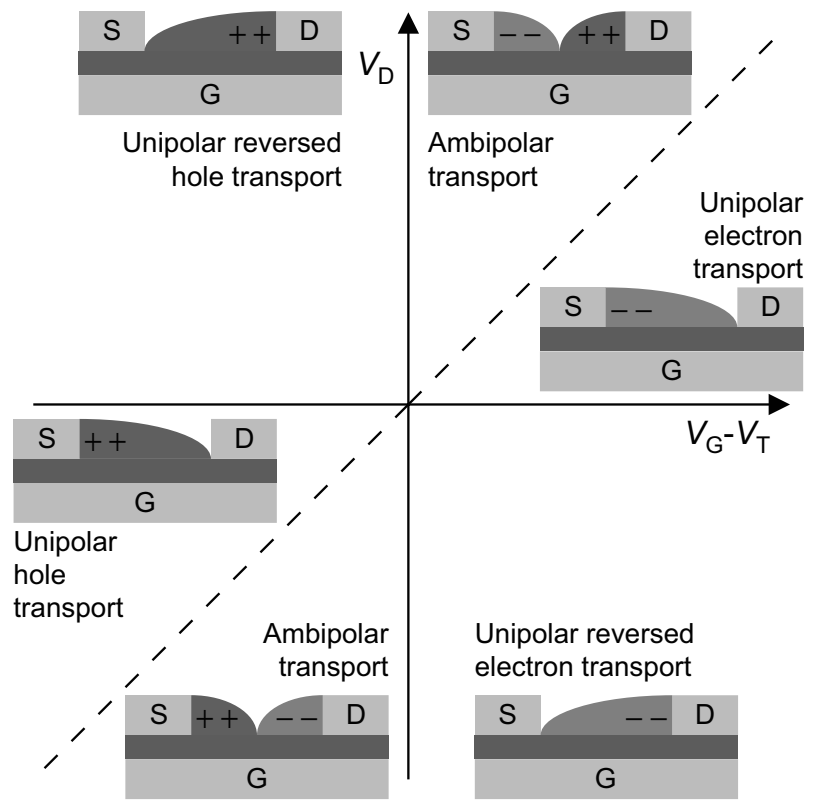

Figure 17.1 Sketch for the unipolar and ambipolar operation regimes of an organic field-effect transistor. $V_{\mathrm{D}}$ denotes the drain voltage, $V_{\mathrm{G}}$ and $V_{\mathrm{T}}$ are gate and threshold voltage, respectively. (see colour plates p. LXXX)

geometry (see Figure 17.2d). The deposition rates were between $0.35 \AA / \mathrm{s}$ for neat films and $1.4 \AA / \mathrm{s}$ for layers with $1: 3$ stoichiometry. The given mixing ratios in this chapter are volume percentages, as the evaporation process was controlled via two independent deposition monitors using quartz microbalances. They are always given in the form $\mathrm{C}_{60}$ : $\mathrm{CuPc}$. Additionally, different substrate temperatures ( $300 \mathrm{~K}$ and $375 \mathrm{~K}$ ) were used during evaporation of the materials.

Organic field-effect transistors were fabricated on highly conductive Si wafers $(1-5 \mathrm{~m} \Omega \mathrm{cm})$ with a $200 \mathrm{~nm}$ or $320 \mathrm{~nm}$ thick thermally grown oxide, which acts as the gate insulator. Photolithographically patterned $\mathrm{Au}(100 \mathrm{~nm}$, using $1 \mathrm{~nm}$ Ti as adhesion layer) source and drain electrodes were made by electron-beam evaporation and by a lift-off process. These structures were cleaned in an ultrasonic bath with solvents (acetone, isopropyl) and ultra-pure water. The substrates were dried with pure nitrogen, treated with an $\mathrm{O}_{2}$-plasma for $60 \mathrm{~s}$ at $200 \mathrm{~W}$ and $0.6 \mathrm{mbar}$, and heated in a fore-vacuum at $400 \mathrm{~K}$ for 2 hours. On some of the samples additionally a treatment of the silicon oxide surface by octadecyltrichlorosilane (OTS) was made before they were heated [26]. This OTS treatment was carried out at room temperature, in a solution of OTS in n-heptane $(0.86 \mathrm{mM})$, in an exsiccator. Subsequently the samples were cleaned of residual OTS in chloroform in an ultrasonic bath. 
(a) Buckminster-Fullerene

$$
\mathrm{C}_{60}
$$

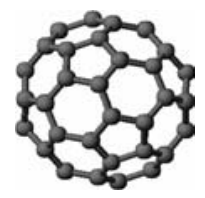

(b) Ring-structure transistor

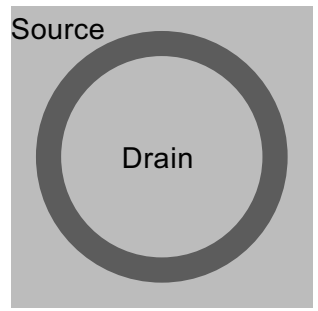

(d)

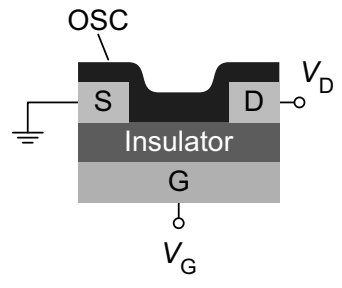

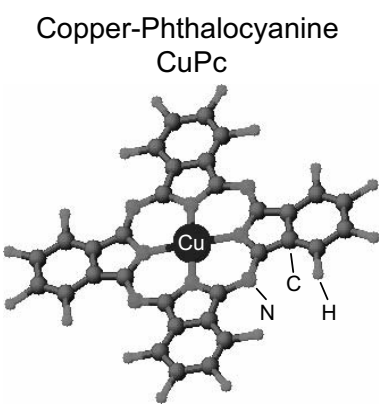

(c) Ring-structure inverter

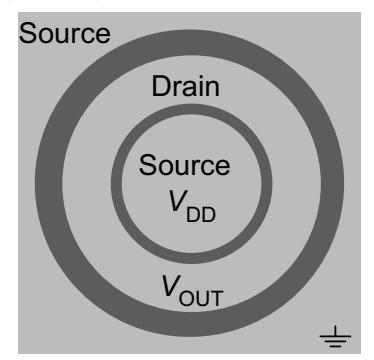

(e)

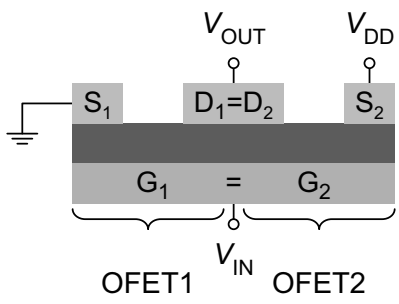

Figure 17.2 (a) Chemical structures of the used materials: fullerene $\left(\mathrm{C}_{60}\right)$ and copper-phthalocyanine $(\mathrm{CuPc})$. Top view (b) and cross section (d) of the ring-type transistor in bottom-gate and bottom-contact geometry. Top view (c) and cross section (d) of the ring-type inverter. The silicon substrate acts as the gate electrode for transistors and inverters. (see colour plates p. LXXXI)

Transistors with a ring-type geometry (see Figure 17.2b) were used, whose source electrodes form a closed ring around the drain electrodes. This prevents parasitic currents from outside of the active transistor channel without the necessity of structuring the organic semiconductor [28]. The channel length and width were $5 \mu \mathrm{m}$ and $2500 \mu \mathrm{m}$, respectively. Ambipolar inverters were made from two transistors stacked into each other (see Figure 17.2c) and have an additional ring channel around the first one. Thus both transistors share the common silicon substrate gate electrode as input of the inverter and the drain 
electrode as output (see Figure 17.2e). Length and width of the outer channel were $10 \mu \mathrm{m}$ and $2500 \mu \mathrm{m}$, respectively, and of the inner channel $8 \mu \mathrm{m}$ and $2000 \mu \mathrm{m}$, respectively. Consequently, the ratio of length to width was the same for both channels. Each substrate $(20 \mathrm{~mm} \times 20 \mathrm{~mm})$ contained 24 individual transistors and 12 inverter structures to allow for a comparison of several devices. Complementary inverters were fabricated by evaporating neat $\mathrm{CuPc}$ and $\mathrm{C}_{60}$ each on one half of a prestructured substrate. For this purpose two evaporation steps were necessary with different shadow masks. In this case two separated transistors, one p-type and one n-type, from different areas on the substrate were connected together to form an inverter.

Without air-exposure the devices were transferred into a vacuum-chamber providing a pressure of less than $5 \times 10^{-6}$ mbar for characterisation. The output and transfer characteristics of the transistors were measured using two independent source-meter units (Keithley 236). In order to measure inverter transfer curves an additional source-meter unit (Keithley 2400) was implemented.

The charge-carrier mobilities $\mu$ and the threshold voltages $V_{\mathrm{T}}$ were extracted from the slope of the transfer characteristics in the saturation region $\left|V_{\mathrm{D}}\right|>\left|V_{\mathrm{G}}-V_{\mathrm{T}}\right|$ using the standard relationship:

$$
I_{\mathrm{D}, \mathrm{sat}}=\frac{W}{2 L} \cdot \mu \cdot C_{\mathrm{Ox}}\left(V_{\mathrm{G}}-V_{\mathrm{T}}\right)^{2}
$$

Here $W$ is the channel width, $L$ is the channel length, $C_{\mathrm{Ox}}$ is the gateoxide capacitance per unit area, $V_{\mathrm{G}}$ is the gate voltage, and additionally $V_{\mathrm{D}}$ is the drain voltage. Mobility $\mu$ and threshold voltage $V_{\mathrm{T}}$ were determined from the linear regression of the measured data plotted as $\sqrt{I_{\mathrm{D} \text {,sat }}}$ vs. $V_{\mathrm{G}}$. The inverter characteristics include the transfer curve $V_{\mathrm{OUT}}$ vs. $V_{\mathrm{IN}}$ as well as the current dissipation $I_{\mathrm{DD}}$ vs. $V_{\mathrm{IN}}$.

$\mathrm{X}$-ray diffraction (XRD) patterns were obtained in $\theta-2 \theta$ geometry using a Siemens $\mathrm{D}-500$ diffractometer $\left(\mathrm{Cu} \mathrm{K} \mathrm{K}_{\alpha}\right.$ radiation with a wavelength of $0.1542 \mathrm{~nm}$ ) for analysing the crystallinity of the films. The morphology investigations were performed using a Thermo Microscopes Auto Probe scanning force microscope (SFM) operated in non-contact (tapping) mode.

For photoelectron spectroscopy organic layers (neat films and mixtures) with a nominal thickness of $25 \mathrm{~nm}$ were deposited on $100 \mathrm{~nm}$ thick gold films which were thermally evaporated onto oxidised $\mathrm{Si}$ wafers. The electronic properties of the films were characterised using X-ray and ultraviolet photoelectron spectroscopy (XPS, UPS) by employing monochromated $\mathrm{Al} \mathrm{K}_{\alpha}$ radiation $(h v=1486.7 \mathrm{eV})$ for measurement of the core levels as well as ultraviolet radiation [He I $(h v=21.2 \mathrm{eV})$ and He II $(h v=40.8 \mathrm{eV})$ ] for an analysis of the occupied states near the Fermi level. For a measurement of the secondary electron cut-off to determine the sample work function exactly, an additional bias $(-2 \mathrm{~V}$ and $-5 \mathrm{~V})$ was applied to the sample. 
35217 Ambipolar Charge Carrier Transport in Organic Semiconductor Blends

\section{3}

\section{Unipolar Field-Effect Transistors}

Output and transfer characteristics of neat $\mathrm{C}_{60}$ and CuPc FETs are shown in Figure 17.3. The output characteristics show the typical unipolar transistor behaviour with linear increase at low drain voltage and saturation at higher $V_{\mathrm{D}}$. The transfer characteristics display an off-regime followed by an increase of drain current with increasing absolute value of the gate voltage exceeding the switch-on voltage.

The analysis of the shown transfer characteristics yielded saturation mobilities for these preparation conditions $\left(\mathrm{O}_{2}\right.$ plasma treatment, $375 \mathrm{~K}$ during evaporation) of $7 \times 10^{-2} \mathrm{~cm}^{2} / \mathrm{Vs}$ for the $\mathrm{C}_{60}$ FET and $6 \times 10^{-4} \mathrm{~cm}^{2} / \mathrm{Vs}$ for the $\mathrm{CuPc}$ FET. The threshold voltages were $+63 \mathrm{~V}$ and $-31 \mathrm{~V}$, respectively.

The measured $I-V$ characteristics show considerable hysteresis between increasing and decreasing voltage sweeps, which can be attributed to dynamic processes in the charging of the semiconductor-dielectric interface [29], originating e.g. from polaron-bipolaron reactions [30] or trap recharging [31]. For further details on this topic refer to Chapter 16 by Paasch et al. The largest hysteresis is present in the output characteristics of the $\mathrm{C}_{60}$ FET. The hysteresis in all other measurements, including the ambipolar FETs, and in particular for the transfer characteristics which were used for the analysis, are significantly smaller.
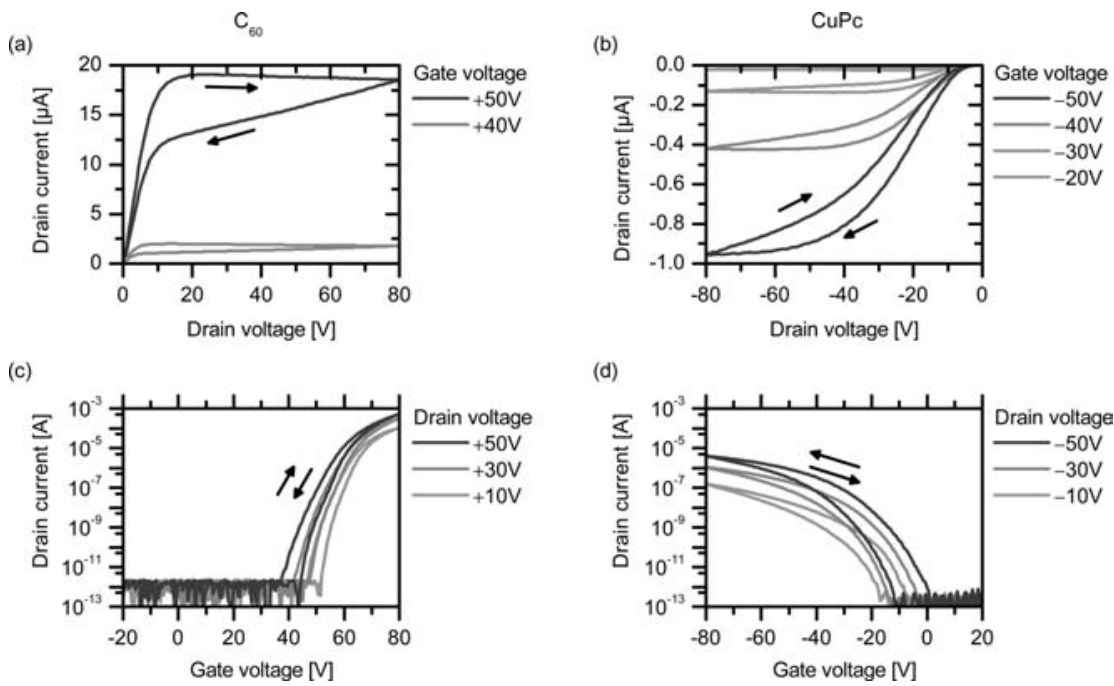

Figure 17.3 Output and transfer characteristics of unipolar field-effect transistors with neat $\mathrm{C}_{60}(\mathrm{a}, \mathrm{c})$ and neat $\mathrm{CuPc}$ $(b, d)$ films. The substrates were treated with $\mathrm{O}_{2}$-plasma and the films evaporated at $375 \mathrm{~K}$ substrate temperature. The direction of the hysteresis is indicated by arrows. (Figure adopted from Ref. [27].) (see colour plates p. LXXXII) 
The curvature in the output characteristics of $\mathrm{CuPc}$ at the origin of the $I-V$ diagram suggests a considerable injection barrier of the contact [32], whereas the linear increase in the $\mathrm{C}_{60} \mathrm{FET}$ indicates a significantly smaller one. As we will show later on (see Section 17.8), this can be related to the electronic structure of the $\mathrm{Au} / \mathrm{CuPc}$ and the $\mathrm{Au} / \mathrm{C}_{60}$ interface, respectively [33-38]. However, it should be noted that other possibilities such as an influence of the adhesion layer [39], or from traps in the semiconductor [40] or from a field-dependent charge carrier mobility [41] have been put forward to account for nonlinearities in the $I-V$ characteristics.

\section{4}

\section{Ambipolar Field-Effect Transistors}

Ambipolar FETs with mixing ratios of $1: 3,1: 1$ and $3: 1$ between $\mathrm{C}_{60}$ and $\mathrm{CuPc}$ have been investigated. All of them showed ambipolar transport with the same qualitative features as the 1:1 mixture displayed in Figure 17.4. Here a strong increase of the current on saturation of the output characteristic (Figure $17.4 \mathrm{a}, \mathrm{b}$ ) is measured for both the $\mathrm{n}$ - and the $\mathrm{p}$-channel regime. This is a clear signature of ambipolar behaviour. Electrons are injected at higher drain volt-

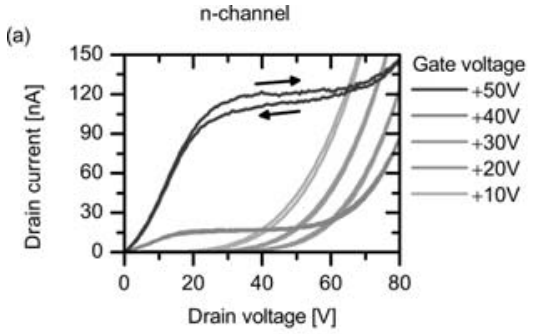

(b)

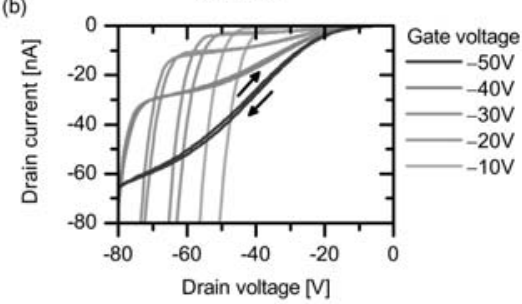

(c)

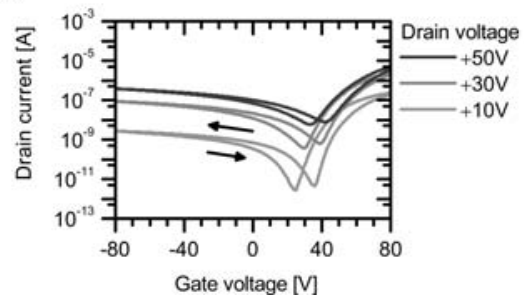

(d)

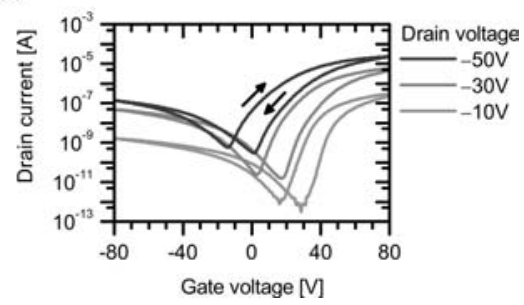

Figure 17.4 Output and transfer characteristics of ambipolar field-effect transistors for a mixing ratio between $\mathrm{C}_{60}$ and $\mathrm{CuPc}$ of $1: 1$ measured in the n-channel regime (a, c) as well as the $\mathrm{p}$-channel regime $(\mathrm{b}, \mathrm{d})$. The substrate was $\mathrm{O}_{2}$-plasma treated and the film evaporated at $375 \mathrm{~K}$ substrate temperature. The direction of the hysteresis is indicated by arrows. (Figure adopted from Ref. [27].) (see colour plates p. LXXXII) 
ages into the hole-conducting channel, and vice versa. Consequently, the transfer characteristics (Figure 17.4c, d) do not show any off regime as the ambipolar increase takes place in the regime where the FET with the neat materials is switched off.

The magnitude of the drain currents in both regimes differs significantly for this mixing ratio. The p-channel (negative $V_{\mathrm{G}}$ ) shows a current which is three orders of magnitude lower than the current in the n-channel (positive $V_{\mathrm{G}}$ ). In both measurements the curvature in the output characteristics at the origin of the $I-V$ diagram suggests injection barriers with non-linear contact resistances. Here this contact resistance is also visible in the electron channel and even more pronounced in the hole channel because the conductivity of both channels is reduced due to mutual dilution of the conducting material by the other species.

\section{5}

\section{Charge Carrier Mobility and Threshold Voltage}

For the analysis of the mobility and the threshold voltage the saturation regime is used here. An analytical model based on the Shockley equation by Schmechel et al. [13] assumes that the electron and hole mobilities as determined from the linear or saturation regime are also valid in the ambipolar regime. As previously shown for the system under consideration, the mobilities determined from the saturation and ambipolar regime are in excellent agreement [27].

Figure 17.5 shows the mobility and the threshold voltage determined from the saturation regime as a function of concentration in the blend for different preparation conditions. We note that these data have been obtained by averaging over several identically prepared samples. The substrate temperature during evaporation of the blends was $25^{\circ} \mathrm{C}$ and $100{ }^{\circ} \mathrm{C}$ for the $\mathrm{O}$-plasma treated silicon oxide surface. The surface chemistry was modified additionally for the $100{ }^{\circ} \mathrm{C}$ substrate temperature by silanisation of $\mathrm{SiO}_{2}$ with OTS.

In all cases, an exponential decrease of both electron and hole mobility is observed upon dilution of the corresponding conducting material with the other species. Remarkably, all blends with different mixing ratios show charge carrier transport for both charge carrier types. This means that there is always a percolation path for both electrons and holes. However, the hopping distance between molecules of the same type is increased upon mixing with the other species thus leading to a decreasing wave-function overlap. This is wellestablished for molecularly doped polymers [42], where a homogenous dilution of conducting molecules in an inert matrix is present. This scenario might even hold for nano-phase separated granular films, for which we have indications from SFM data (see below). In this case the mobility limiting step would be the hopping between grains where the average distance should also increase upon dilution. 


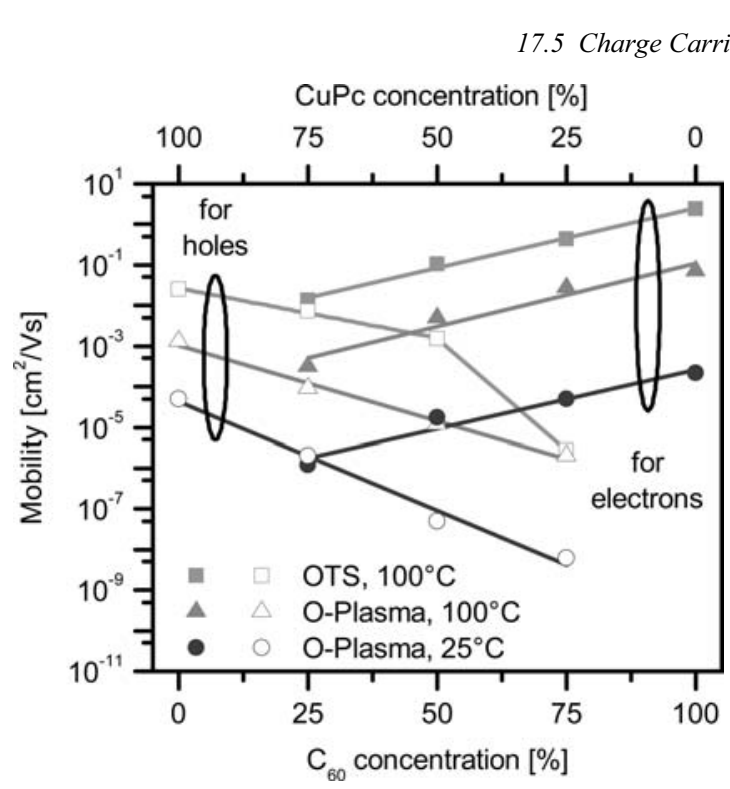

Figure 17.5 Mobility

(above) and threshold voltage (below) as determined from transfer characteristics in the saturation regime of OFETs with different composition, substrate temperature and substrate treatment. The filled symbols are related to the electron transport, the open symbols to the hole transport. (see colour plates p. LXXXIII)

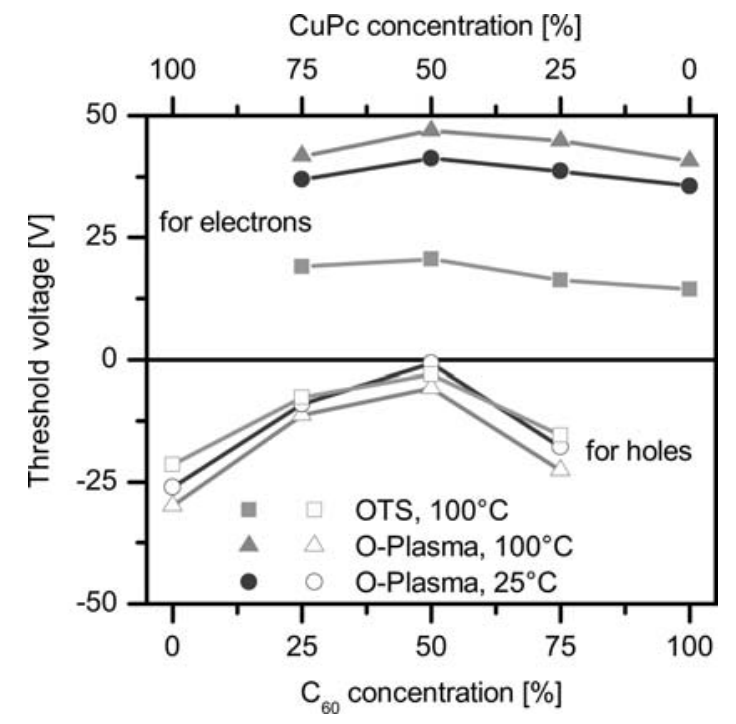

As compared with film growth at room temperature, an increased mobility is found for the higher substrate temperature and a further increase is realised by lowering the surface energy with OTS. This increase of mobility was reported for unipolar OFETs [43] and is also valid for these blends. Interestingly, for all treatments balanced mobilities are found at about $25 \% \mathrm{C}_{60}$ content.

At this point it is noteworthy to compare our results on the variation of charge carrier mobilities with composition of the blends to other ambipolar mixed systems. There are on the one hand polymer-fullerene blends used for photovoltaic applications (in particular MDMO-PPV:PCBM) [44, 45] and on 
the other hand blends of molecular materials implemented again in photovoltaic devices (mostly phthalocyanine: $\mathrm{C}_{60}$ ) [46] and ambipolar light-emitting transistors [47]. In both types of blend systems one observes as a common feature a strong (in many cases exponential) decrease of the mobility of one carrier type with increasing dilution by the other component. (A remarkable exception from this rule is the hole mobility in polymer-fullerene blends in which the addition of fullerene molecules even improves $\mu_{\mathrm{h}}$. In this case a stretching of the polymer chains occurs, leading to improved interchain hopping [45].)

It is remarkable, however, that despite a roughness which is larger than the film thickness in some of our films (see below), all of them show n-channel as well as p-channel transport. Obviously, there still exists a percolation path for conduction in both materials independent of phase separation and order formation. We also note that the bulk morphology does not necessarily provide precise information for organic field-effect transistors since in these devices the active channel is restricted to the first few molecular layers at the interface to the gate dielectric [48-50].

The threshold voltage shows a dependence on the mixing ratio for the hole channel, but not for the electron channel. By contrast, the threshold voltage for the electron channel changes with the preparation conditions, especially with the OTS passivation of the silicon oxide. The reason is that the O-plasma treated oxide surface contains $\mathrm{OH}$-groups which are acting as electron traps and increase the threshold voltage for electrons [14]. By surface treatment with OTS these traps are at least partially passivated and the threshold voltage decreases. The change of threshold voltage for the hole transport with the concentration is related to the organic/organic interface in the $\mathrm{CuPc} / \mathrm{C}_{60}$ blend [27] and can be explained by a hole accumulation at the $\mathrm{CuPc}$ side of the $\mathrm{C}_{60} / \mathrm{CuPc}$ interface [36]. Because there is no charge transfer from $\mathrm{CuPc}$ to $\mathrm{C}_{60}$ in the ground state this shift should be related to a redistribution of charges within the $\mathrm{CuPc}$ molecules in the presence of $\mathrm{C}_{60}$ as demonstrated by calculations [51]. As expected, this charge displacement is independent of the preparation conditions. The threshold voltage shift is related to an interface charge [32] at the organic/organic interface in the proximity of the insulator by:

$$
\Delta V_{\mathrm{T}}=\frac{e \times N_{\text {If }}}{C_{\mathrm{Ox}}}
$$

By modelling the molecular packing [27] a charge accumulation of about 0.012 charges per molecule is estimated. The calculated charge transfer in an ideal complex of one $\mathrm{C}_{60}$ and one $\mathrm{CuPc}$ molecule was calculated to be 0.06 charge per molecule [51], 5 times higher than determined here. 
17.6

\section{Film Morphology and Structure}

In order to get more insight into the concentration dependent electron and hole mobility, structure and morphology of neat and mixed films (evaporated at $375 \mathrm{~K}$ ) were investigated by X-ray diffraction and scanning force microscopy. XRD measurements (Figure 17.6) show a strong (200) peak corresponding to the $\alpha$-phase for the neat $\mathrm{CuPc}$ film and a weak (200) peak for the film with a $1: 3$ mixture, whereas for all other mixtures including neat $\mathrm{C}_{60}$ films no diffraction peaks are detectable, indicating a structure without coherent diffraction, e.g. amorphous or very small crystallites. These observations are in full agreement with measurements reported on $\mathrm{CuPc}: \mathrm{C}_{60}$ mixtures for photovoltaic applications by Rand et al. [46]. The authors observed a disappearance of the $\mathrm{CuPc}$ diffraction peak for a fullerene content of more than about $15 \%$ and asserted no peak corresponding to $\mathrm{C}_{60}$, although, as in our case, the electron mobility in neat $\mathrm{C}_{60}$ films was about two orders of magnitude higher than the hole mobility in CuPc. Other groups have obtained crystalline $\mathrm{C}_{60}$ films, however, only at elevated substrate temperatures of about $440 \mathrm{~K}$ during evaporation [52].

Figure 17.7 shows the surface morphologies for different mixing ratios as investigated by non-contact SFM for small areas. Neat $\mathrm{CuPc}$ films have a needle-like structure, corresponding to the $\alpha$-phase structure observed in XRD. This film shows a low root mean square roughness (RMS) of only $2.2 \mathrm{~nm}$. Also the Laue oscillations beside the diffraction peak for the neat $\mathrm{CuPc}$ film (see Figure 17.6) are an indication of a well defined film thickness. For neat $\mathrm{C}_{60}$ films a rough and granular structure is observed. Compared with the $\mathrm{CuPc}$ film, the roughness of the films is increasing with increasing $\mathrm{C}_{60}$ content.

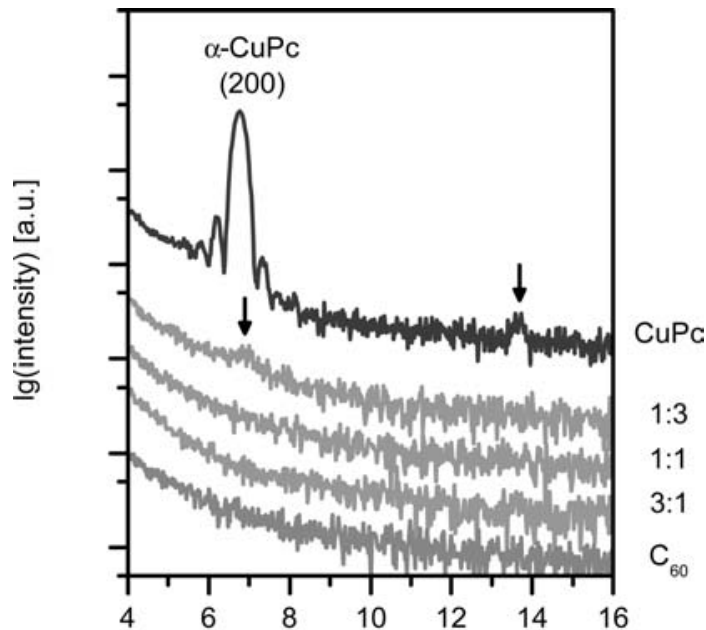

$2 \theta[\mathrm{deg}]$
Figure 17.6 X-ray diffraction patterns for neat $\mathrm{CuPc}$ and $\mathrm{C}_{60}$ films as well as for three mixed films grown at $375 \mathrm{~K}$. The arrows indicate the weak (200) peak in the sample with a mixing ratio of $1: 3$ and the second order diffraction peak of the neat $\mathrm{CuPc}$ sample. (see colour plates p. LXXXIV) 


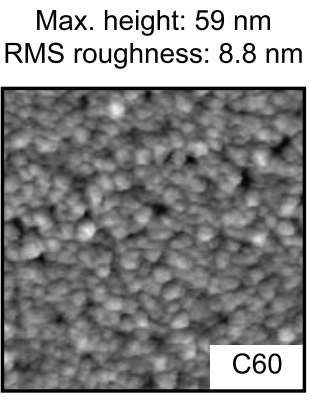

Max. height: $11 \mathrm{~nm}$ RMS roughness: $2.2 \mathrm{~nm}$

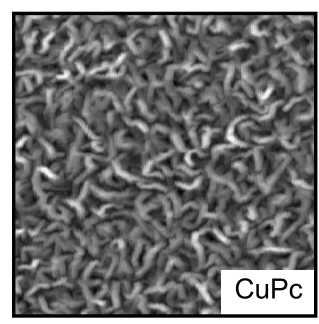

SFM $2 \times 2 \mu \mathrm{m}^{2}$

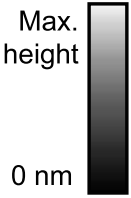

Max. height: $33 \mathrm{~nm}$ RMS roughness: $5.2 \mathrm{~nm}$

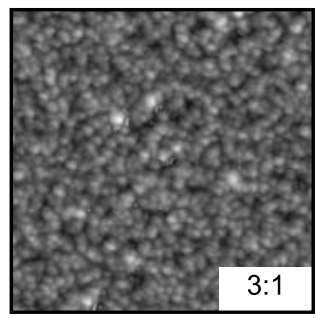

Max. height: $38 \mathrm{~nm}$ RMS roughness: $6.5 \mathrm{~nm}$

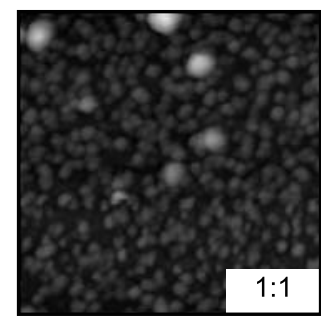

Max. height: $8 \mathrm{~nm}$ RMS roughness: $1.2 \mathrm{~nm}$

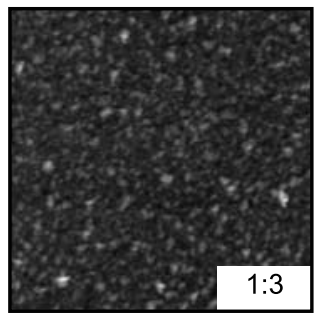

Figure 17.7 Scanning force microscopy images taken in non-contact mode for neat $\mathrm{C}_{60}$ and $\mathrm{CuPc}$ films as well as for three mixed films grown at $375 \mathrm{~K}$. The total image size is $2 \times 2 \mu \mathrm{m}^{2}$. The max. height is given as the difference between the lowest value (dark blue) and the highest value (white) in each of the images. (see colour plates p. LXXXIV)

We note that we have also investigated films deposited without substrate heating by XRD and SFM (not shown here). These films are much smoother (RMS roughness of only $2.3 \mathrm{~nm}$ in all cases) and do not have such large grains. In particular, the neat $\mathrm{CuPc}$ film does not show a needle-like morphology in agreement with work by Schultes et al. [54]. However, in contrast, to this work there is no indication of an $\alpha$ to $\beta$ conversion for our CuPc film grown at elevated temperature. For both preparation conditions the XRD data indicate the presence of the $\alpha$-phase.

The film roughness has also been studied by XPS measurements of neat films and blends deposited on Au covered Si wafers (for details see next section). In this technique the intensity ratio $I_{\mathrm{Au} 4 \mathrm{f}} / I_{\mathrm{Cls}}$ of the Au4f and the $\mathrm{C} 1 \mathrm{~s}$ core level peaks can be used as a measure of the homogeneity in the film thickness. As shown in Figure 17.8 the Au substrate signal is zero for a closed and flat $\mathrm{CuPc}$ film and increases with increasing $\mathrm{C}_{60}$ content indicating film roughening. Here it is important to remember that measurements using SFM are a very local probe whereas XPS measurements sample a much larger area. Nevertheless both techniques show a similar trend for the roughness of the blended films. 


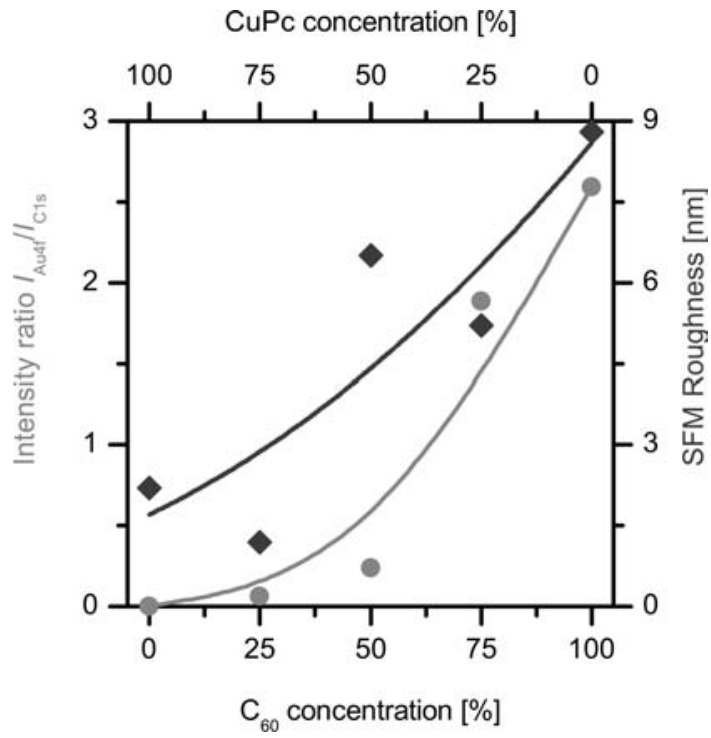

17.7 Electronic Structure 359

Furthermore phase separation of $\mathrm{C}_{60}$ and $\mathrm{CuPc}$ is described at elevated temperatures [55] which affects the molecular arrangement, but can not be detected by the techniques used here. Altogether, film morphology and structure of blends of flat $\mathrm{CuPc}$ and spherical $\mathrm{C}_{60}$ molecules are still not very well understood and need further investigation. This will become particularly important in photovoltaic cells, where this material combination is a potentially promising candidate for so-called bulk-heterojunction cells [21, 56].

\section{7}

\section{Electronic Structure}

For analysing the electronic structure the neat and mixed organic films were deposited on gold films that were pretreated in an oxygen plasma prior to the deposition of the organic materials. This treatment was chosen instead of in situ preparation of the gold layer under high-vacuum conditions to realise the same electrode properties as in OFETs. It should be noted that transporting the gold films through ambient air after the oxygen plasma treatment leads to the formation of a conductive hydrocarbon layer [57]. The work function of gold covered by this hydrocarbon layer is determined by photoelectron spectroscopy (PES) to be $4.2 \mathrm{eV}$, whereas a clean gold substrate (after removal of the adsorbed species by $\mathrm{Ar}^{+}$ion bombardment) exhibits a work function of $5.4 \mathrm{eV}$.

Figure 17.9 shows the important results of the XPS and UPS measurements. The CuPc C1s spectrum contains the $\mathrm{C}-\mathrm{C}$ bond $\left(E_{\mathrm{B}}=284.2 \mathrm{eV}\right.$, indicated by small ticks $)$ and the chemically shifted $\mathrm{C}-\mathrm{N}\left(E_{\mathrm{B}}=285.6 \mathrm{eV}\right)$ bond, as well as their $\pi-\pi^{*}$ satellites. For $\mathrm{C}_{60}$ only one pronounced feature is visible at $E_{\mathrm{B}}=284.7 \mathrm{eV}$. Both spectra are in agreement with published results on pristine 
materials $[33,58]$. The composition of the blends and the $\mathrm{CuPc}$ and $\mathrm{C}_{60}$ related $\mathrm{C} 1 \mathrm{~s}$ peak positions are determined by fitting the spectra of the mixed films with Gauss-Lorentz-functions using the shape of the neat $\mathrm{C}_{60}$ and $\mathrm{CuPc}$ core levels. As shown in Figure 17.9a the energetic positions of the $\mathrm{C} 1 \mathrm{~s}$ features are slightly shifting upon addition of $\mathrm{C}_{60}$. The N1s spectra (not shown) were also analysed for the peak position and found to behave in a similar manner.

The electronic structure of the occupied states near the Fermi level (measured using He II radiation) is shown in Figure $17.9 \mathrm{~b}$. The maxima of the HOMO levels of the neat materials are indicated by small ticks. Whereas the $\mathrm{CuPc} \mathrm{HOMO}$ level is clearly separated for all mixed films, the HOMO level of $\mathrm{C}_{60}$ is only visible in films with a concentration of $77 \%$ and $100 \%$. For smaller amounts of $\mathrm{C}_{60}$ in the films the HOMO level is present only as a shoulder in the occupied molecular orbitals of CuPc. Again, the spectra can be described as a linear superposition of neat material spectra if a shift of the energetic position is included.

The work function of the films was determined from the secondary electron cut-off in the He I spectra with applied bias (see Figure 17.9c). As for the core and the HOMO levels an energy shift of the secondary electron cut-off with the film composition is present.

The graph in Figure 17.10 shows a comparison of the obtained vacuum levels of the organic films and the substrate $\left(E_{\mathrm{Vac}}^{\mathrm{Org}}\right.$ and $\left.E_{\mathrm{Vac}}^{\mathrm{Sub}}\right)$, of the HOMO levels $\left(E_{\mathrm{HOMO}}^{\mathrm{Org}}\right)$ (defined as the HOMO edge near the Fermi level), as well as of the $\mathrm{C} 1 \mathrm{~s}$ and $\mathrm{N} 1 \mathrm{~s}$ core levels $\left(E_{\mathrm{Cls}}^{\mathrm{Org}}\right.$ and $\left.E_{\mathrm{Nls}}^{\mathrm{Org}}\right)$ depending on the mixing ratio. The ionisation energy of the neat films is $6.2 \mathrm{eV}$ for $\mathrm{C}_{60}$ and $5.0 \mathrm{eV}$ for $\mathrm{CuPc}$ in agreement with the literature [36] and the difference of the work function amounts to about $\sim 0.5 \mathrm{eV}$.

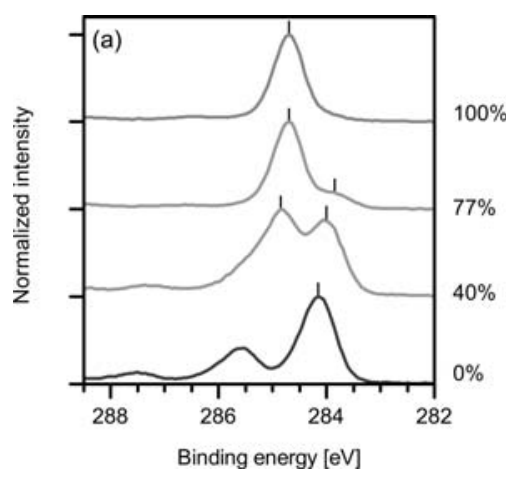

Figure 17.9 XPS and UPS measurements of neat and different mixed films of $\mathrm{C}_{60}$ and CuPc: (a) $\mathrm{C} 1 \mathrm{~s}$ spectra (excitation: monochromated $\mathrm{Al} \mathrm{K}$ ), (b) HOMO levels (excitation: He II) and (c) secondary electron cut-off (excitation: He I and
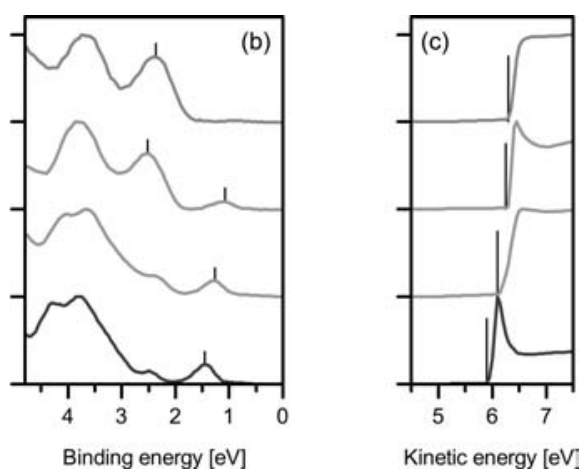

$V_{\text {Bias }}=-2 \mathrm{~V}$ ). The numbers on the right side of the diagram (a) give the $\mathrm{C}_{60}$ concentration as determined from the measurements shown in part (a). (Figure adopted from Ref. [53].) (see colour plates p. LXXXV) 


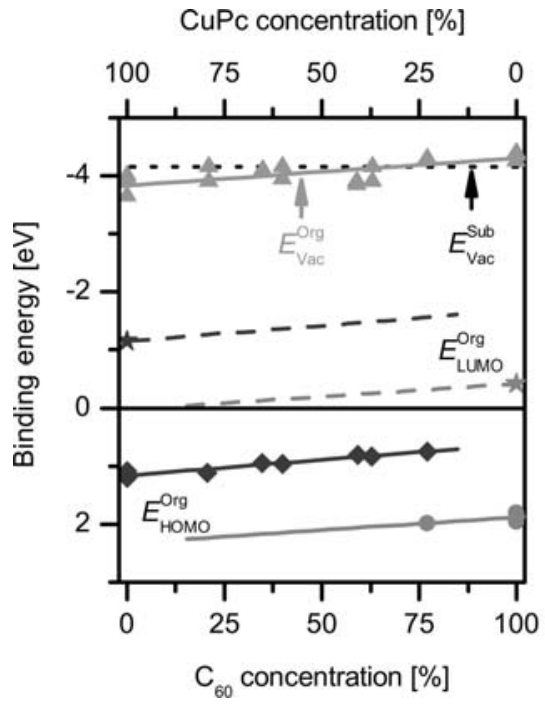

Figure 17.10 Position of the vacuum level, the high energy edge of the HOMO level, and the $\mathrm{C} 1 \mathrm{~s}$ and $\mathrm{N} 1 \mathrm{~s}$ core levels as a function of the $\mathrm{C}_{60} / \mathrm{CuPc}$ mixing ratio. The $\bullet$ and the $\bullet$ symbols are representing the measured values for $\mathrm{C}_{60}$ and $\mathrm{CuPc}$ related levels, respectively, and the symbols the measured work functions. The solid lines are linear fits of the
17.7 Electronic Structure CuPc concentration [\%]

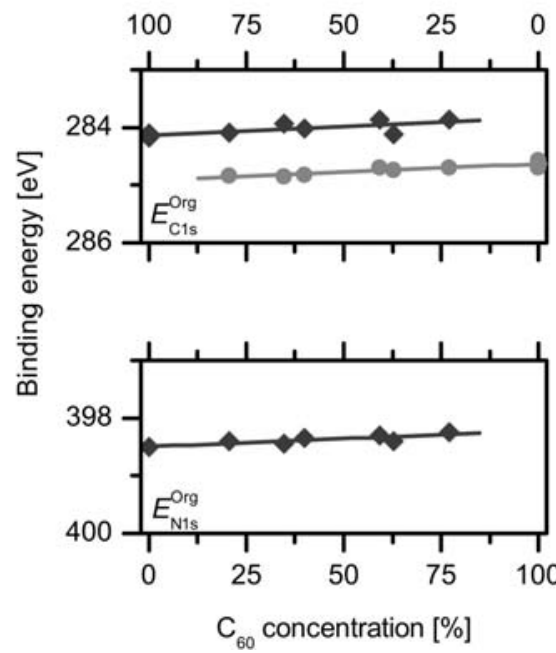

corresponding measured values. The constant dotted line is the vacuum energy of the gold substrate (covered by a conductive hydrocarbon layer). The LUMO levels of the neat materials are marked with the $\star$ symbols. The dashed lines are extrapolated LUMO levels for the blends. (Figure adopted from Ref. [53].) (see colour plates p. LXXXVI)

It is remarkable that the secondary electron cut-offs used to determine the work function of all mixtures were sharp and did not show a double step that would reflect two different local surface potentials [59], although the films have a nanogranular morphology as determined by atomic force microscopy [27]. Thus, the blends show a common vacuum level which shifts linearly with the concentration between the work functions of the neat materials given by $\Phi_{\mathrm{CuPc}}=3.8 \mathrm{eV}$ and $\Phi_{\mathrm{C}_{60}}=4.3 \mathrm{eV}$. The linear change of the work function in our studies suggests that $\mathrm{CuPc} / \mathrm{C}_{60}$ mixtures are electronically non-interacting (unless they are optically excited).

Taking all the results together, there is no evidence for a ground state charge transfer in blends of $\mathrm{CuPc}$ and $\mathrm{C}_{60}$. The core level spectra can be described solely with the scaled features of the neat materials. Also the occupied molecular orbitals do not show additional structures unknown from the neat materials $[36,51]$. The analysis of the difference between the occupied levels (core and HOMO levels) and the vacuum level shows for all compositions a constant ionisation energy. This is manifested in identical shifts of the core levels, the HOMO levels and the vacuum level with the concentration of the blends. Thus the molecular levels are simply following the change of the common vacuum energy. 
Figure 17.10 allows some important conclusions for charge carrier injection in organic semiconductor blends to be drawn. For this purpose one also needs information on the lowest unoccupied molecular orbitals (LUMO) of the films. Unfortunately, up till now there are no direct measurements of the LUMO level for blends but only for the neat materials [37, 38]. However, one can take these data obtained from inverse photoemission and extrapolate them towards blends using the same shift of the LUMO levels that was observed for all other levels. In other words, we assume that the energy gaps of both materials of $2.3 \mathrm{eV}[37,38]$ stay constant in the mixture. This seems to be a reasonable hypothesis, as there is no indication for charge transfer between both materials in the ground state that would lead to new features in the electronic structure. Postulating that this model is correct, one can derive the injection barriers for both electrons and holes from the shown energy level diagram. The obtained values are given in Figure 17.11a. First, one notices that the injection barrier for holes into $\mathrm{CuPc}$, i.e. the difference between the HOMO of $\mathrm{CuPc}$ and the Fermi level of $\mathrm{Au}$ (which is the reference level at binding energy zero) is larger than the respective injection barrier for electrons into $\mathrm{C}_{60}$. This is in excellent agreement with the output characteristics discussed before (see Figure 17.3). Furthermore, both injection barriers are predicted to decrease from neat materials towards blends. This feature will be investigated separately in the next section when we analyse contact resistances in OFETs.

Before going to this, we would like to point out another interesting conclusion from the energy level diagram of these ambipolar blends which is related to photovoltaic cells based on $\mathrm{CuPc}$ and $\mathrm{C}_{60}$ as a donor-acceptor system. Upon photoexcitation, excitons generated in either of the two materials (within the reach of the respective exciton diffusion lengths) will be dissociated at the organic-organic interface leading to electrons in the LUMO of $\mathrm{C}_{60}$ and holes in the HOMO of CuPc. This charge separation leads to a gradient of the chemical potential at the interface that drives the photocurrent through the cell [60]. Thus the magnitude of the HOMO-LUMO offset between both materials will be related to the driving force, for which the open-circuit voltage can serve as an easily accessible experimental quantity. The obtained electronic structure therefore allows the conclusion that the HOMO-LUMO offset in blends is significantly smaller than at the heterojunction between neat layers of $\mathrm{CuPc}$ and $\mathrm{C}_{60}$ [53]. Preliminary measurements have indeed shown that the open-circuit voltage in a bulk-hetero junction organic photovoltaic cell (1:1 mixture) is about $0.2 \mathrm{~V}$ smaller than in a cell comprising a planar interface between $\mathrm{CuPc}$ and $\mathrm{C}_{60}[61,67]$.

\section{8}

\section{Charge Carrier Injection}

Information on charge carrier injection was obtained from analysing contact resistances in OFETs. In contrast to Section 17.5, we now use transfer curves 
(a)

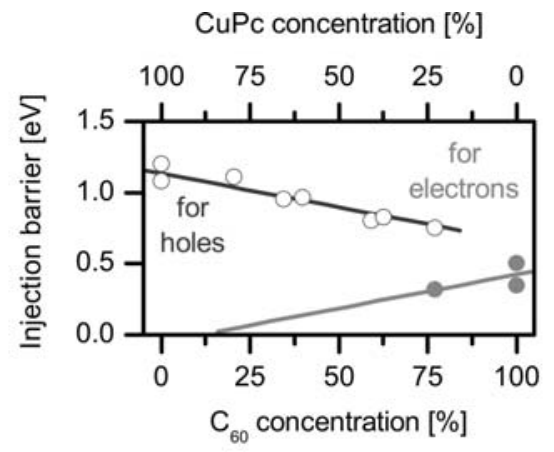

(b)

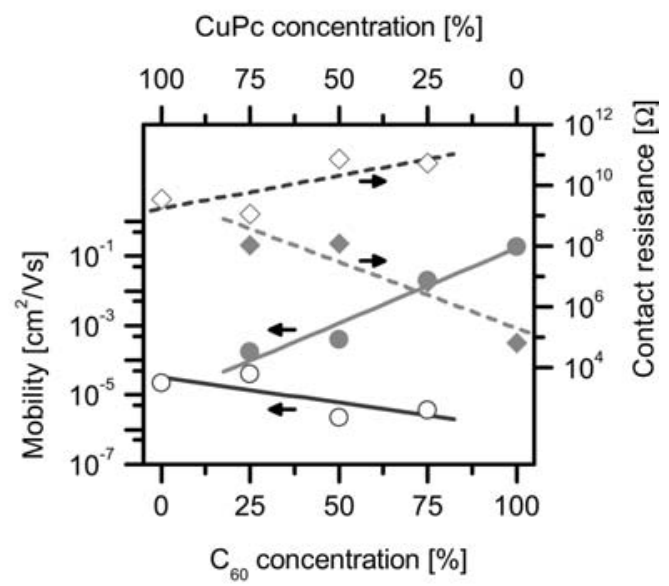

(c)

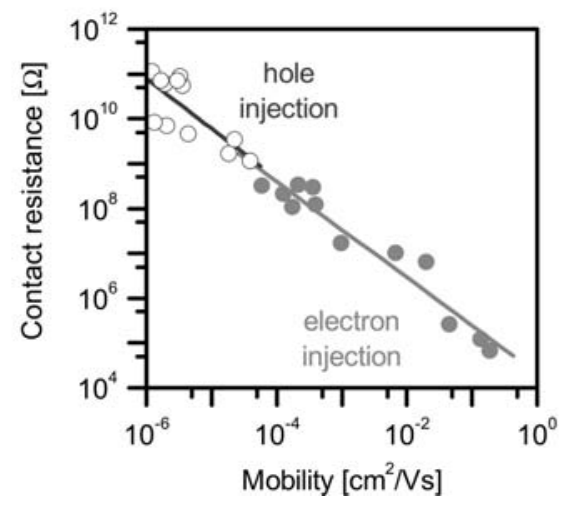

Figure 17.11 (a) Injection barrier determined from UPS (compare with Figure 17.10). (b) Mobility (solid line) and contact resistance (dashed line) as determined from transfer characteristics in the linear regime for $\left|V_{\mathrm{G}}-V_{\mathrm{T}}\right|=33 \mathrm{~V}$. (c) Relation between mobility and contact resistance for different $\left|V_{\mathrm{G}}-V_{\mathrm{T}}\right|>\left|V_{\mathrm{D}}\right|$ and different mixing ratios $\left(0,25,50,75\right.$ and $\left.100 \% \mathrm{C}_{60}\right)$. The straight lines are linear fits related to the vacuum level shift in part (a) and to guide the eyes in the parts (b) and (c). (see colour plates $\mathrm{p}$. LXXXVII) 
in the linear range. Following a procedure suggested by Horowitz [62] the drain voltage in the Shockley equation is replaced by the drain voltage corrected by the contact resistance $\left(V_{\mathrm{D}} \rightarrow V_{\mathrm{D}}-I_{\mathrm{D}} \cdot R_{\mathrm{C}}\right)$. As a result the drain current is given by

$$
I_{\mathrm{D}}=\frac{(W / L) \cdot C_{\mathrm{Ox}} \cdot \mu \cdot\left(V_{\mathrm{G}}-V_{\mathrm{T}}\right) \cdot V_{\mathrm{D}}}{1+(W / L) \cdot C_{\mathrm{Ox}} \cdot \mu \cdot\left(V_{\mathrm{G}}-V_{\mathrm{T}}\right)}
$$

Using the channel conductance $g_{\mathrm{d}}=\partial I_{\mathrm{D}} / \partial V_{\mathrm{D}}$ and the transconductance $g_{\mathrm{m}}=\partial I_{\mathrm{D}} / \partial V_{\mathrm{G}}$ the mobility $\mu$ and the contact resistance $R_{\mathrm{C}}$ were calculated from

$$
\sqrt{\mu} \cdot\left(V_{\mathrm{G}}-V_{\mathrm{T}}\right)=\frac{g_{\mathrm{d}}}{\sqrt{g_{\mathrm{m}}}} \cdot \sqrt{\frac{L V_{\mathrm{D}}}{W C_{\mathrm{Ox}}}}
$$

and

$$
R_{\mathrm{C}}=\frac{1}{g_{\mathrm{d}}}-\frac{L}{W \cdot \mu \cdot C_{\mathrm{Ox}} \cdot\left(V_{\mathrm{G}}-V_{\mathrm{T}}\right)} .
$$

In this calculation the dependence of $\mu$ and $R_{\mathrm{C}}$ on $V_{\mathrm{G}}$ is neglected for the derivatives. To minimise the error of this simplification the mobilities and the contact resistances are plotted in Figure $17.11 \mathrm{~b}$ for $V_{\mathrm{D}}=10 \mathrm{~V}$ at a constant $\left|V_{\mathrm{G}}-V_{\mathrm{T}}\right|=33 \mathrm{~V}$ (using O-plasma treatment and $100{ }^{\circ} \mathrm{C}$ substrate temperature). Once again, one observes decreasing mobilities with decreasing concentration of the transport material, as in the saturation regime shown in Figure 17.5 and the contact resistance increases upon dilution. This behaviour is in contrast to the injection barrier shown in Figure 17.11a, which decreases with decreasing amount of the respective transport material, and can be taken as a clear indication that an additional mechanism has to be taken into account in the injection process.

First, there is a pure geometrical effect, meaning that the effective contact area will decrease if less molecules of one type are present in the mixture. However, this would only lead to a linear change of both mobility and contact resistance with the mixing ratio that can not account for the observed variation over several orders of magnitude. Thus as a second possibility, we consider the case that the injection process is influenced by the same increase of the intermolecular hopping distance as discussed before for the mobility. Therefore, we plot in Figure 17.11c the contact resistance vs. mobility for all presented mixing ratios and for different charge carrier densities (related to different values of $\left.\left|V_{\mathrm{G}}-V_{\mathrm{T}}\right|\right)$. A reciprocal relation $R_{\mathrm{C}} \sim \mu^{-1}$ is observed indicating that in the presented system the mobility limits the injection of charge carriers. This behaviour can be explained by diffusion limited injection [32] following the equation

$$
j_{\text {inj }} \sim \mu \cdot \exp \left[-\frac{\Phi_{\mathrm{B}}}{k T}\right] .
$$


This mechanism was already identified in organic photoconductors [63] varying the mobility by mixing semiconducting and insulating molecules and in unipolar OFETs [64] varying the mobility by the charge carrier concentration. Thus our investigations show that mixing of organic semiconductors has important consequences for both charge carrier injection and transport which will be relevant in various kinds of devices, including not only OFETs, but also OPV cells and OLEDs. (Actually, it was already demonstrated in OLEDs that grading interfaces can enhance device efficiency by reducing energy barriers at organic/organic interfaces and probably also enhancing recombination rates by slowing down carriers [65].)

\section{9}

\section{Ambipolar and Complementary Inverter}

As already mentioned, there was the suggestion of using ambipolar FETs to realise complementary-like organic integrated circuits $[3,10,17,66]$. Here we investigate ambipolar inverters consisting of mixed-layer ambipolar FETs and compare their characteristics to a complementary inverter made of discrete $\mathrm{p}$ - and n-channel transistors from neat materials.

Ambipolar inverters or complementary-like inverters are based on two ambipolar transistors (Figure 17.12a). These inverters are working with a positive and a negative driving voltage whereby the sign of the driving voltage determines which of the two transistors works as n- and p-transistor (Figure 17.12b). Complementary inverters in contrast to this are based on unipolar $\mathrm{n}$ - and p-transistors with a defined power supply, as shown in either Figure $17.12 \mathrm{~b}$ or Figure 17.12c. However, to realise such a circuit patterning of the organic semiconductor or locally different surface functionalisation are required to achieve spatially separated p- and n-conducting regions, which is not necessary in the case of ambipolar inverters. In order to evaluate the performance of these different concepts we have fabricated both ambipolar and complementary inverters and compared their output characteristics both by experimental studies und simulations.

(a)

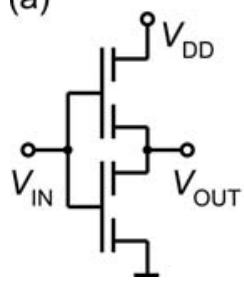

(b)

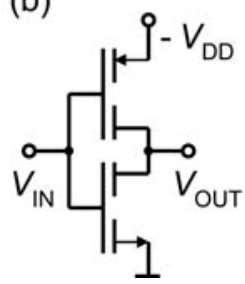

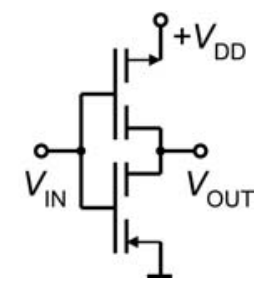

Figure 17.12 (a) Electrical circuit for an ambipolar inverter. (b) The two operation regimes (positive and negative supply voltage) for ambipolar and complementary inverters. 
Figure 17.13a, b show the characteristics of ambipolar inverters using layers with mixing ratios of $3: 1$ and $1: 3$. The upper part presents the transfer characteristics of the inverters (output voltage vs. input voltage) and the lower part the corresponding current supplied by $V_{\mathrm{DD}}= \pm 90 \mathrm{~V}$, which directly gives the dissipated current in the circuit.

A characteristic feature of ambipolar inverters is their operation in the first as well as in the third quadrant of the output-vs.-input diagram, depending on the sign of the supply voltage only. Ideally an inverter should have a sharp transition from the low to the high state at half of the driving voltage and the dissipated current should be negligibly small except for a narrow range around the transition voltage. Both inverters, based on two ambipolar transistors, show this transition at about half of the supply voltage $\left(V_{\mathrm{DD}} / 2= \pm 45 \mathrm{~V}\right)$ and reach high gain (about 13 for the 1:3 mixture and about 18 for the $3: 1$ mixture), which is defined as the steepness of the characteristics at the transitions between the high and the low states. However, they do not reach zero in the low state and the driving voltage in the high state. Also the voltages at the high and the low state are not constant.

The noise margin is an indicator of the tolerance of cascaded inverter stages. To demonstrate this, Figure 17.13 also contains the inverter characteristics mirrored at the bisecting line, which can be considered as the output of a following inverter. The noise margin is then defined as the largest possible square between these two curves. In this case the noise margin amounts to about $14 \mathrm{~V}$ for the $1: 3$ mixture and about $19 \mathrm{~V}$ for the $3: 1$ mixture.
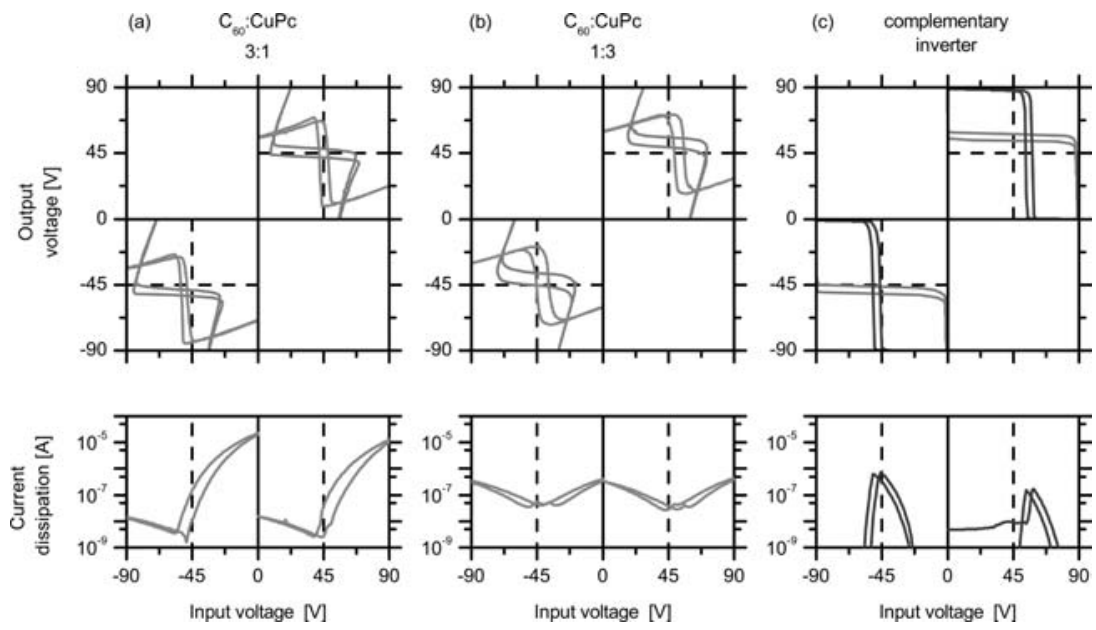

Figure 17.13 Characteristics of ambipolar (top) and current dissipation (bottom) are inverters with mixing ratios of $3: 1$ (a) and shown. The substrates were $\mathrm{O}_{2}$-plasma $1: 3$ (b) and a complementary inverter (c) consisting of a neat $\mathrm{C}_{60}$ and a neat $\mathrm{CuPc}$ transistor. The driving voltage is $V_{\mathrm{DD}}= \pm 90 \mathrm{~V}$. Transfer characteristics treated and the films evaporated at $375 \mathrm{~K}$ substrate temperature. The grey lines are shown to explain the noise margin (see text). (Figure adopted from Ref. [27].) (see colour plates p. LXXXVIII) 
17.9 Ambipolar and Complementary Inverter

Significant differences between the two ambipolar inverters are observed in the dissipated current. Whereas for the inverter with a $1: 3$ mixing ratio the power dissipation is symmetric around $\pm 45 \mathrm{~V}$, the device with a $3: 1$ mixture shows an asymmetry of about three orders of magnitude. Moreover, the dissipated current is as high as $10^{-5} \mathrm{~A}$, which is one-and-a-half orders of magnitude larger than in the previous case. Thus, it is remarkable that a huge asymmetry in electron and hole mobilities of more than three orders of magnitude, as observed for the 3:1 mixture (see Figure 17.5), has drastic consequences for the power dissipation of the inverter, although it does not lead to a significant asymmetry in the transition voltage.

For comparison we have also fabricated a complementary inverter by connecting a p-channel transistor (neat $\mathrm{CuPc}$ ) and an n-channel transistor (neat $\mathrm{C}_{60}$ ) together, its characteristics being shown in Figure 17.13c. In order to make it operate in the first quadrant it is necessary to connect the p-channel transistor to $+V_{\mathrm{DD}}$ and the n-channel transistor to ground and vice versa, the $\mathrm{n}$ channel transistor to $-V_{\mathrm{DD}}$ and the p-channel transistor to ground in order make it operate in the third quadrant, as seen in Figure 17.12. These inverters also show slightly asymmetric transitions with respect to $\pm V_{\mathrm{DD}} / 2$ due to the unbalanced electron and hole mobilities in neat $\mathrm{CuPc}$ and $\mathrm{C}_{60}$, but they reach the ground potential in the low state and the supply voltage in the high state. The gain is about 38 and the noise margin is about $29 \mathrm{~V}$ for a positive supply voltage, respectively, $34 \mathrm{~V}$ and $32 \mathrm{~V}$ for a negative supply voltage. So these values are about twice as high as those of the ambipolar inverters. A characteristic difference of the ambipolar inverter type is the current dissipation being high only in the vicinity of the transition. This is because at any time one of the two transistors is being switched off in each of the logic states whereas an ambipolar transistor always shows a non-negligible current.

For a better understanding of inverter characteristics we performed numerical simulations based on the analytical model of Schmechel et al. [13] for both ambipolar and complementary inverters. The output voltage as well as the current dissipation was calculated to demonstrate the differences between ambipolar and complementary inverters and the influence of device parameters like mobility and threshold voltage.

Figure 17.14 shows simulated transfer characteristics of ambipolar and complementary inverters. In the left picture balanced mobilities $\left(\mu_{\mathrm{e}}=\mu_{\mathrm{h}}\right)$ and symmetric threshold voltages $\left(V_{\mathrm{T}, \mathrm{e}}=-V_{\mathrm{T}, \mathrm{h}}=30 \mathrm{~V}\right)$ were used for the simulation. The picture in the middle shows the characteristics for symmetric threshold voltages $\left(V_{\mathrm{T}, \mathrm{e}}=-V_{\mathrm{T}, \mathrm{h}}=30 \mathrm{~V}\right)$ but different mobilities $\left(\mu_{\mathrm{e}}=100 \mu_{\mathrm{h}}\right)$. Whereas, in the right picture balanced mobilities $\left(\mu_{\mathrm{e}}=\mu_{\mathrm{h}}\right)$ and different threshold voltages $\left(V_{\mathrm{T}, \mathrm{e}}=+30 \mathrm{~V}, V_{\mathrm{T}, \mathrm{h}}=-10 \mathrm{~V}\right)$ were used. In all cases, as observed before in the measurements, the output voltage of the complementary inverter reaches the driving and the ground voltage in the high and the low state, respectively, whereas the output voltage of the ambipolar inverter does not [10]. Thus the noise margin of the ambipolar inverters are lower than for the complementary inverters. Nevertheless the gain for both types of inverters 
is comparably high. As expected, the current dissipation in the complementary inverter has a maximum at the transition between the logic levels, whereas the ambipolar inverter has its minimum at this point.

A closer look at the simulations in Figure 17.14a, which are based on symmetric mobilities and threshold voltages, shows that the transition between the logic states is at half of the driving voltage for both the ambipolar and the complementary inverter. An asymmetry in carrier mobilities (Figure 17.14b) and/or in threshold voltages (Figure 17.14c) leads to a shift of the transition voltage in both cases. Nevertheless, the transition voltages of the measured inverters (Figure 17.14a, c) are still more or less symmetric although the mobilities are largely different. The reason is that in both cases the shift of the transition voltage due to the higher mobility in the n-channel is compensated by a lower threshold voltage in the p-channel. One can further see that different mobilities have no influence on the gain, whereas different, especially lower, threshold voltages decrease both the gain and the noise margin. Experimentally, we have a decrease of the threshold voltage in the p-channel by diluting $\mathrm{CuPc}$ with $\mathrm{C}_{60}$ (Figure 17.5) and accordingly the gain in the measured ambipolar inverters is lower than in the complementary inverter. Finally, it is evident that the current dissipation of an ambipolar inverter is increasing drastically in the case of asymmetric mobilities. Altogether, complementary inverters are clearly superior to their ambipolar counterparts, but in both cases equal mobilities and symmetric threshold voltages are required to achieve optimal inverter characteristics.
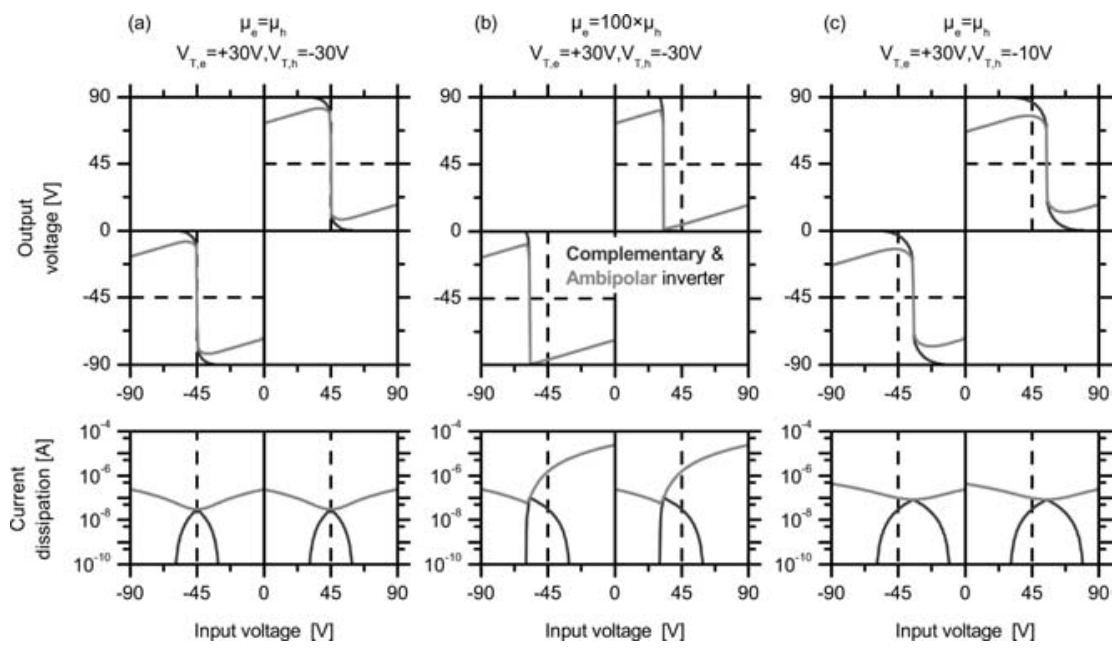

Figure 17.14 Simulations of ambipolar and complementary inverter transfer characteristics and current dissipation with (a) symmetric mobility and threshold voltage for $\mathrm{p}$ - and n-channel in comparison with (b) asymmetric mobilities and (c) asymmetric threshold voltages. (see colour plates p. LXXXVIII) 
17.10 Summary $\mid \mathbf{3 6 9}$

17.10

Summary

Mixtures of hole conducting $\mathrm{CuPc}$ and electron conducting $\mathrm{C}_{60}$ show ambipolar transport for all investigated mixing ratios. However, the mobilities of electrons and holes are strongly dependent on the composition indicating that percolation is a critical issue. Unlike in polymer/fullerene blends, there is no evidence for strong structural interactions, rather, the materials simply dilute each other. This is manifested also by the electronic structure of the blends, which does not show any significant evidence for charge transfer in the ground state.

Due to the higher electron mobility in neat $\mathrm{C}_{60}$ (as compared with the hole mobility in neat $\mathrm{CuPc})$, an excess of $\mathrm{CuPc}(75 \%)$ is required to achieve balanced mobilities. But even with equal electron and hole mobilities an ambipolar inverter is inferior to a complementary one with discrete $\mathrm{p}$ - and n-channel transistors. Thus realising true complementary logic circuits will require devising efficient patterning methods, e.g. by locally different functionalisation of the gate insulator. In this context we note that it has recently been shown that neat films and single crystals of $\mathrm{CuPc}$ can exhibit both electron and hole transport as well as ambipolar transport, if the surface of the gate dielectric is passivated in order not to trap electrons and if contacts with suitable work function are used $[68,69]$.

Furthermore, our investigations of the electronic structure allow the conclusion that the HOMO-LUMO offset is significantly smaller in blends as compared with planar interfaces between both materials. Together with the lowering of the charge carrier mobility this reduction of the "built-in field" could have important consequences for photovoltaic cells based on these molecular materials. Bulk heterojunction devices with homogeneously mixed donor/ acceptor layers will not necessarily be the optimal film morphology. The challenge will be to grow suitable blend morphologies with interdigitated donor/acceptor phases that simultaneously have large interfacial area and high exciton diffusion and charge carrier drift length for efficient charge carrier generation and extraction.

\section{Acknowledgements}

This work was supported by the Deutsche Forschungsgemeinschaft through Sonderforschungsbereich 484 and Schwerpunktprogramm 1121. The authors thank M. Himmerlich, J. A. Schaefer, and S. Krischok (TU Ilmenau, Germany) for the cooperation concerning photoelectron spectroscopy and J. Pflaum (Uni Stuttgart, Germany) for XRD measurements. 
370 17 Ambipolar Charge Carrier Transport in Organic Semiconductor Blends

\section{References}

1. W. Warta and N. Karl, Phys. Rev. B 32, 1172-1182 (1985).

2. C. D. Dimitrakopoulos and P. R. L. Malenfant, Adv. Mater. 14, 99-117 (2002).

3. E. J. Meijer, D. M. De Leeuw, S. Setayesh, E. Van Veenendaal, B. H. Huisman, P. W. M. Blom, J. C. Hummelen, U. Scherf, and T. M. Klapwijk, Nature Mater. 2, 678-682 (2003).

4. C. J. Brabec, V. Dyakonov, J. Parisi, and N. S. Sariciftci, Organic Photovoltaics (Springer Verlag, 2003).

5. G. W. Neudeck and A. K. Malhotra, J. Appl. Phys. 46, 239- 247 (1975).

6. J. Locklin, K. Shinbo, K. Onishi, F. Kaneko, Z. N. Bao, and R. C. Advincula, Chem. Mater. 15, 1404-1412 (2003).

7. J. G. Xue and S. R. Forrest, Phys. Rev. B 69, 245322 (2004).

8. J. Wang, H. B. Wang, X. J. Yan, H. C. Huang, and D. H. Yan, Appl. Phys. Lett. 87, 093507 (2005).

9. R. B. Ye, M. Baba, Y. Oishi, K. Mori, and K. Suzuki, Appl. Phys. Lett. 86, 253505 (2005).

10. Y. Inoue, Y. Sakamoto, T. Suzuki, M. Kobayashi, Y. Gao, and S. Tokito, Jpn. J. Appl. Phys. 144, 3663-3668 (2005).

11. M. A. Loi, C. Rost-Bietsch, M. Murgia, S. Karg, W. Rieß, and M. Muccini, Adv. Funct. Mater. 16, 41-47 (2006).

12. T. Yasuda, T. Goto, K. Fujita, and T. Tsutsui, Appl. Phys. Lett. 85(11), 2098-2100 (2004).

13. R. Schmechel, M. Ahles, and H. von Seggern, J. Appl. Phys. 98, 084511 (2005).

14. L. L. Chua, J. Zaumseil, J. F. Chang, E. C. W. Ou, P. K. H. Ho, H. Sirringhaus, and R. H. Friend, Nature 434, 194-199 (2005).

15. M. Ahles, R. Schmechel, and H. von Seggern, Appl. Phys. Lett. 85, 44994501 (2004).
16. E. C. P. Smits, T. D. Anthopoulos, S. Setayesh, E. van Veenendaal, R. Coehoorn, P. W. M. Blom, B. de Boer, and D. M. de Leeuw, Phys. Rev. B 73, 205316 (2006).

17. T. D. Anthopoulos, S. Setayesh, E. Smith, M. Cölle, E. Cantatore, B. de Boer, P. W. M. Blom, and D. M. de Leeuw, Adv. Mater. 18, 1900-1904 (2006).

18. J. Rostalski and D. Meissner, Sol. Energy Mater. Sol. Cells 61, 87-95 (2000).

19. T. Stübinger and W. Brütting, J. Appl. Phys. 90(7), 3632 - 3641 (2001).

20. P. Sullivan, S. Heutz, S. M. Schultes, and T. S. Jones, Appl. Phys. Lett. 84(7), 1210-1212 (2004).

21. J. G. Xue, B. P. Rand, S. Uchida, and S. R. Forrest, J. Appl. Phys. 98, 124903 (2005).

22. G. Paasch, T. Lindner, C. RostBietsch, S. Karg, W. Rieß, and S. Scheinert, J. Appl. Phys. 98, 084505 (2005).

23. A. Hepp, H. Heil, W. Weise, M. Ahles, R. Schmechel, and H. von Seggern, Phys. Rev. Lett. 91, 157406 (2003).

24. C. Rost, S. Karg, W. Rieß, M. A. Loi, M. Murgia, and M. Muccini, Appl. Phys. Lett. 85, 1613-1615 (2004).

25. J. Zaumseil, R. H. Friend, and H. Sirringhaus, Nature Mater. 5, 69-74 (2006).

26. S. Grecu, M. Roggenbuck, A. Opitz, and W. Brütting, Org. Electron. 7, 276-286 (2006).

27. A. Opitz, M. Bronner, and W. Brütting, J. Appl. Phys. 101, 063709 (2007).

28. E. J. Meijer, C. Detcheverry, P. J. Baesjou, E. van Veenendaal, D. M. de Leeuw, and T. M. Klapwijk, J. Appl. Phys. 93, 4831-4835 (2003).

29. N. Marjanovic, T. B. Singh, G. Dennler, S. Gunes, H. Neugebauer, N. S. Sariciftci, R. Schwödiauer, and S. Bauer, Org. Electron. 7, 188-194 (2006). 
30. R. Tecklenburg, G. Paasch, and S. Scheinert, Adv. Mater. Opt. Electron. 8(6), 285-294 (1998).

31. T. Lindner, G. Paasch, and S. Scheinert, J. Appl. Phys. 98, 114505 (2005).

32. S. Sze, Physics of Semiconductor Devices (Wiley, New York, 1982).

33. M. Knupfer and $H$. Peisert, phys. stat. sol. (a) 201, 1055-1074 (2004).

34. O. V. Molodtsova, T. Schwieger, and M. Knupfer, Appl. Surf. Sci. 252, 143-147 (2005).

35. S. C. Veenstra and H. T. Jonkman, J. Polym. Sci. B 41, 2549-2560 (2003).

36. O. V. Molodtsova and M. Knupfer, J. Appl. Phys. 99, 053704 (2006).

37. I. Hill, A. Kahn, Z. Soos, and R. Pascal, Chem. Phys. Lett. 327, 181-188 (2000).

38. R. W. Lof, M. A. Vanveenendaal, B. Koopmans, H. T. Jonkman, and G. A. Sawatzky, Phys. Rev. Lett. 68, 3924- 3927 (1992).

39. Y. Nobuhide, N. Makoto, H. Nobukazu, N. Kazumasa, W. Masaru, and K. Jiro, Appl. Phys. Lett. 85(20), 4663 - 4665 (2004).

40. T. Lindner, G. Paasch, and S. Scheinert, J. Mater. Res. 19(7), 2014-2027 (2004).

41. S. Cherian, C. Donley, D. Mathine, L. LaRussa, W. Xia, and N. Armstrong, J. Appl. Phys. 96, 5638-5643 (2004).

42. P. M. Borsenberger and D. S. Weiss, Organic Photoreceptors for Imaging Systems (Marcel Dekker Ltd, New York, 1993).

43. C. K. Song, B. W. Koo, S. B. Lee, and D. H. Kim, Jpn. J. Appl. Phys. 141, 2730-2734 (2002).

44. S. M. Tuladhar, D. Poplavskyy, S. A. Choulis, J. R. Durrant, D. D. C. Bradley, and J. Nelson, Adv. Funct. Mater. 15, 1171-1182 (2005).

45. V. D. Mihailetchi, L. J. A. Koster, P. W. M. Blom, C. Melzer, B. de Boer, J. K. J. van Duren, and R. A. J. Janssen, Adv. Funct. Mater. 15, 795-801 (2005).
46. B. P. Rand, J. G. Xue, S. Uchida, and S. R. Forrest, J. Appl. Phys. 98, $124902(2005)$.

47. F. Dinelli, R. Capelli, M. A. Loi, M. Murgia, M. Muccini, A. Facchetti, and T. J. Marks, Adv. Mater. 18, 1416 (2006).

48. G. Horowitz, R. Hajlaoui, and P. Delannoy, J. Phys. III (France) 5, 355-371 (1995).

49. G. Paasch, P. H. Nguyen, and S. L. Drechsler, Synth. Met. 97(3), 255-265 (1998).

50. F. Dinelli, M. Murgia, P. Levy, M. Cavallini, F. Biscarini, and D. M. de Leeuw, Phys. Rev. Lett. 92, 116802 (2004).

51. L. Lozzi, V. Granato, S. Picozzi, M. Simeoni, S. La Rosa, B. Delly, and S. Santucci, J. Vac. Sci. Technol. A 24, 1668-1675 (2006).

52. D. Faiman, S. Goren, E. A. Katz, M. Koltun, N. Melnik, A. Shames, and S. Shtutina, Thin Solid Films 295, 283-286 (1997).

53. A. Opitz, M. Bronner, W. Brütting, M. Himmerlich, J. A. Schaefer, and S. Krischok, Appl. Phys. Lett. 90, 212112 (2007).

54. S. M. Schultes, P. Sullivan, S. Heutz, B. M. Sanderson, and T. S. Jones, Mater. Sci. Eng. C, Biomim. 25, 858-865 (2005).

55. M. Stöhr, T. Wagner, M. Gabriel, B. Weyers, and R. Möller, Adv. Funct. Mater. 11, 175-178 (2001).

56. T. Stübinger and W. Brütting, SPIE Proc. 4465, 102-112 (2002).

57. S. Rentenberger, A. Vollmer, E. Zojer, R. Schennach, and N. Koch, J. Appl. Phys. 100, 053701 (2006).

58. T. R. Ohno, Y. Chen, S. E. Harvey, G. H. Kroll, J. H. Weaver, R. E. Haufler, and R. E. Smalley, Phys. Rev. B 44, 13747-13755 (1991).

59. G. Koller, B. Winter, M. Oehzelt, J. Ivanco, F. P. Netzer, and M. G. Ramsey, Org. Electron. 8, 63-68 (2007). 
Organic Electronics : Structural and Electronic Properties of OFETs, C. Woell (Ed.), (2009)

372

17 Ambipolar Charge Carrier Transport in Organic Semiconductor Blends

60. B. A. Gregg, MRS Bull. 30, 20-22 (2005).

61. W. Brütting, M. Bronner, M. Götzenbrugger, and A. Opitz, Macromol. Symp. 268, 38-42 (2008).

62. G. Horowitz, R. Hajlaoui, D. Fichou, and A. El Kassmi, J. Appl. Phys. 85, 3202-3206 (1999).

63. Y. L. Shen, M. W. Klein, D. B. Jacobs, J. C. Scott, and G. G. Malliaras, Phys. Rev. Lett. 86, 3867-3870 (2001).

64. B. H. Hamadani and D. Natelson, Appl. Phys. Lett. 84, 443-445 (2004).

65. H. Riel, S. Barth, T. Beierlein, W. Brütting, S. Karg, P. Müller, and
W. Rieß, SPIE Proc. 4105, 167-174 (2001).

66. G. W. Neudeck, K. Y. Chung, and H. F. Bare, IEEE Trans. Electron Devices 34, 866-871 (1987).

67. A. Opitz, M. Bronner, J. Wagner, M. Götzenbrugger, and W. Brütting, SPIE Proc. 7002, 70020J (2008).

68. A. Opitz, M. Kraus, M. Bronner, J. Wagner, and W. Brütting, New J. Phys. 10, 065006 (2008).

69. R. W. I. de Boer, A. F. Stassen, M. F. Craciun, C. L. Mulder, A. Molinari, S. Rogge, and A. F. Morpurgo, Appl. Phys. Lett., 86, 262109 (2005). 